\title{
Factors affecting modern urban environment
}

\author{
Botir Giyasov ${ }^{1}$ and Timur Giyasov ${ }^{1, *}$ \\ ${ }^{1}$ Moscow State University of Civil Engineering, Yaroslavskoe shosse, 26, Moscow, 129337, Russia
}

\begin{abstract}
The deterioration of modern urban environment caused by rapid development of megalopolises is becoming increasingly important. The development of modern cities, necessitated by the need to improve the living conditions, results in the creation of new buildings and structures, the development of transport and engineering facilties. As a result, the density of built-up areas, the congestion of transport networks increases, which leads to environmental pollution and complicates the environmental situation in cities. The article is devoted to the analysis of the environement of major cities in Russia. The main factors influencing environmental pollution, characteristic only of modern cities, have been identified. The relationship between energy consumption by various industries and environmental pollution has been established. Based on a comparative analysis of harmful emissions in the most environmentally unfriendly cities of Russia, the role of urban transport in increasing the level of urban pollution is described. The main causes aggravating urban environment are indicated. These include significant high-density development development, which leads to a high concentration of harmful substances that pollute the city.
\end{abstract}

\section{Introduction}

Improving the environment of modern big cities is becoming increasingly important. A modern city with high-density urban development and rapidly developing transport networks is the main cause of unfavorable environment, which is one of the reasons for the decrease in the average life expectancy of people, an increase in the level of morbidity and mortality. According to scientists, the health of the urban population is $20 \%$ dependent on the natural environment. Urban residents are more likely to suffer from cardiovascular diseases, respiratory diseases, and have blood circulation problems.

The environment with the natural landscape of the area is environmentally friendly for humans and all living things. The natural environment of the area, which has been forming for centuries, is undergoing significant changes as a result of the rapid development of the construction industry. As a result, the aerodynamic, temperature and environmental conditions of the environment are changing [1-3].

In the process of development of large cities, the man-made negative impact on the biosphere is enormous. Human beings are part of the eco-system, so the changes caused by human activities have negative the consequences for themselves. This is complicated by the

* Corresponding author: dandyr@mail.ru 
lack of a unified approach among civil engineers, architects, hygienists and environmentalists to the process of creating a favorable living environment.

Changes in the environment occur in the process of constant growth of the need to create a living environment. The creation and improvement of the living environment necessitates new structures to meet the people's needs, such as education, entertainment, recreational activities, cultural development. These are a part of urban life and contribute to the active growth of modern buildings and structures, changing environmental conditions.

In addition, the combination of conditions and factors characteristic of a residential urban environment encourages residents of populated areas to carry out their nonproductive activities, which also affects the characteristics of the environment. The living environment as a whole consists of the environmental characteristics of specific urban objects in which a person stays during the day, week, months and years in accordance with the algorithm of their life. The impact of changes in the living environment on a human being is complex, and comprises the sum of the environmental impacts of specific objects and their parameters [4-6].

As a rule, industrial cities with city-forming enterprises tend to develop rapidly. The development of the city entails the development of urban space, an increase in the number of modern civil facilities and engineering and transport networks. As a result, the number of modern engineering and transport facilities is also increasing. A modern city dweller spends a certain amount of time in these facilities and is exposed to their negative impact. Moreover, the development of urban facilities has a negative impact on the environment. The impact of factors on the environment and humans arising in the development of urban space remains relevant [7-9].

\section{Materials and methods}

One of the main negative factors in a modern city is air pollution caused by emissions from transport, industry and civilian facilities. Due to the active development of the urban structure, the energy consumption of transport, industry and civilian facilities is increasing. An increase in the density of urban development leads to an increase in the number of cars, which is accompanied by an increase in the volume of energy consumption and harmful emissions from vehicles.

Thus, modern urban development with a developed transport networks is one of the causes of environment degradation, while urban transport should be considered as one of the important sources of pollution.

As can be seen from Figure 1, environmental pollution is mainly caused due to the consumption of fuel and energy resources by various industries and sectors [10].

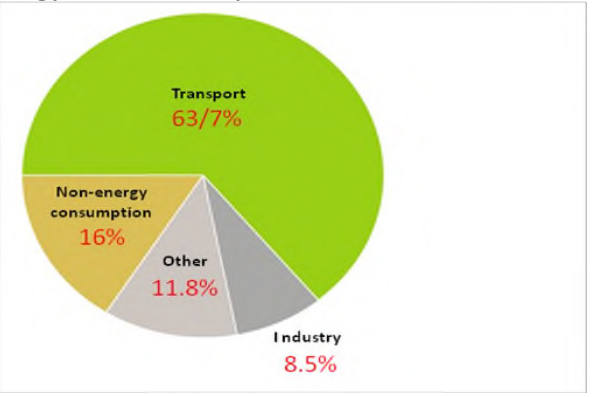

Fig 1. Consumption of oil products by industry.

From the analysis of these data, it follows that in modern cities transport is the main consumer of fuel and energy resources, the use of which increases the amount of harmful emissions into the environment. 
On the other hand, if we consider energy consumption as a whole, then all civil buildings consume more energy than all industries with their factories, plants, metallurgical plants and transport with all its cars, trains and motor ships. (Figure 2) Diagram 2 shows the distribution of energy consumption in Europe [4].

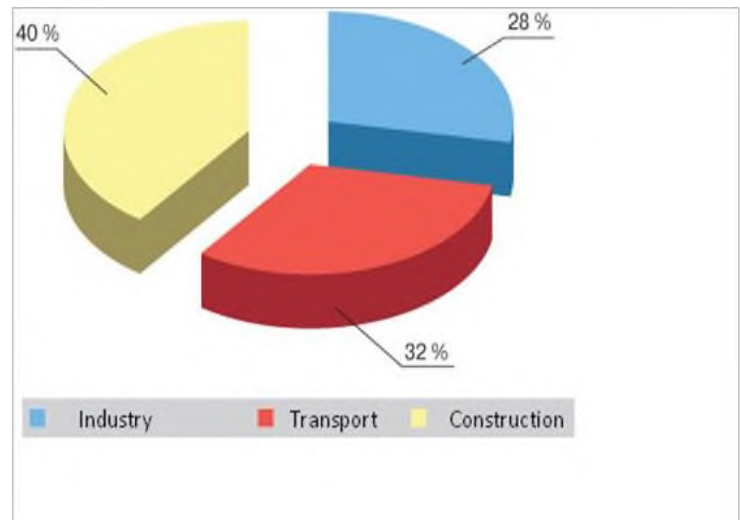

Fig.2. Consumption of energy by industry.

Such intensive consumption, accompanied by constant emissions, also increases the level of urban pollution. Consequently, energy consumption caused by the development of urban development should also be considered as one of the main factors affecting the environment.

Another cause of the urban environemnt degradation is the density of urban development, consisting of complex architectural structures, which have a significant impact on the prevailing aerodynamics of the area. Such unfavorable environmental conditions are observed not only in the industrial part of the city, but also in the residential areas with densely located high-rise buildings. In the air basin of a densely built-up urban environment, the concentration of pollution sources due to the human activity, as well as due to the use of vehicles, exceeds the permissible standards. The aerodynamics of the terrain and the activity of urban transport, disturbed as a result of the influence of urban development, create vast and stable zones in cities with an increased concentration of pollutants. In an urban environment, air stagnation is formed in some areas of residential development, where air velocities range from 0 to $1 \mathrm{~m} / \mathrm{s}$. [11,12] . Such no-wind conditions, formed due to the violation of the aerodynamics of the urban environment, are one of the important causes of environment degradation.

On the one hand, the development of modern cities leads to an increase in energy consumption accompanied by active emissions of pollutants; on the other hand, it increases the density of urban development, which leads to a decrease in the intensity of natural aeration of the urban space. Therefore, it can be argued that the environment of modern cities directly depends on the intensity of their development.

The Ministry of Natural Resources and Environment of the Russian Federation monitors the volume of harmful emissions into the atmosphere, according to which the dirtiest cities for 2019 were identified. Experts have found that the level of pollution is increasing every year. Based on the analysis of these data, Fig. 3 presents a diagram in of harmful emissions in the cities of Russia with the worst environment. 


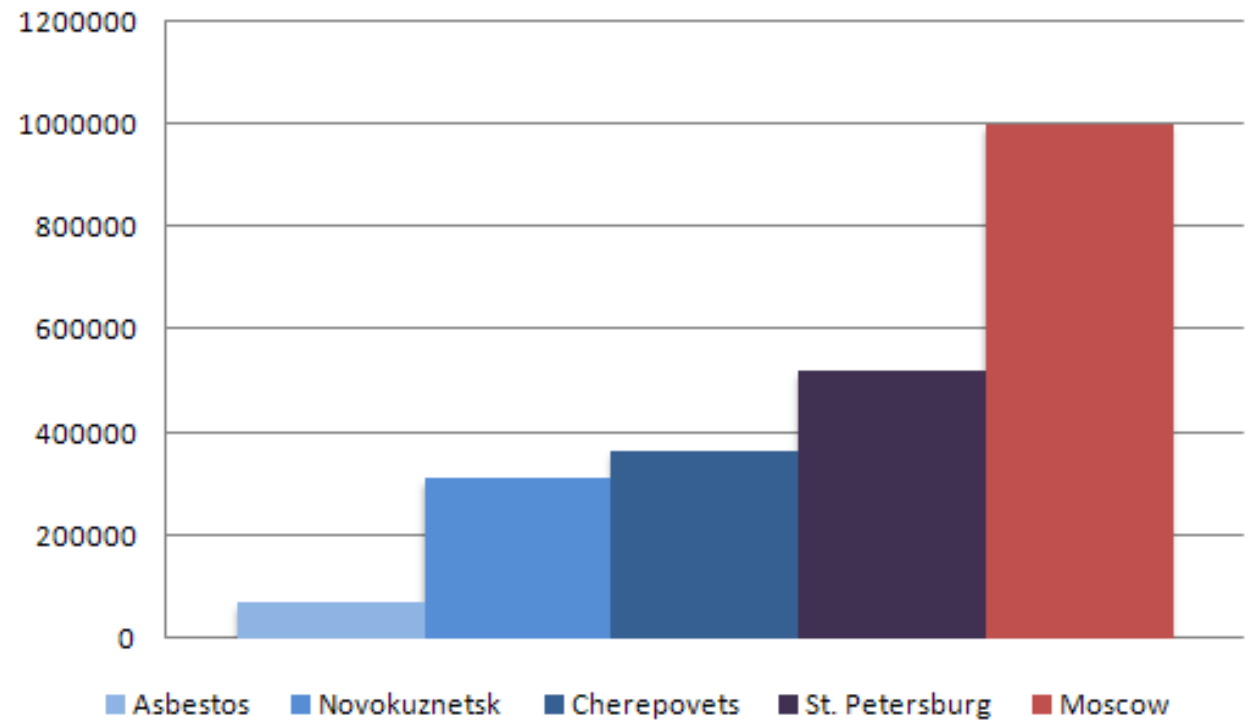

Fig.3. Diagram of harmful emissions in Russian cities (tons per year).

The comparative analysis of these data allows us to determine the main sources of pollution for different cities.

For example, in the city of Asbestos, despite its small population, only 68,000 people, more than 300,000 tons of harmful substances are released into the air every year. the name of the city suggests, one of the main enterprises in the city is an asbestos mining and processing plant. Its dust is carcinogenic and belongs to the 1st hazard class, which causes great damage to human health. Also, the company specialising in the manufacutre of silicate bricks is referred to as harmful industries.

The city of Novokuznetsk is also included in the list of large industrial centers of Russia. Its air pollutes 310,000 tons of substances per year. Much of this pollution comes from coal mines and metallurgical plants.

The city of Cherepovets is a big producer of ferrous metals. Approximately 365,000 tons of pollutants are emitted into the atmosphere there annually. The main source of the pollution is an industrial giant - the Severstal Plant. The chemical industry which specializes in production of chemical fertilizers from nitrogen and phosphates causes the environment degradation.

In the city of St. Petersburg, emissions from urban transport city-forming enterprises are approximately 520,000 tons annually. Similarly to the capital, St. Petersburg is polluted mainly by car exhaust fumes. They account for $85 \%$ of the total pollution of the city on the Neva.

Of course, Moscow as the largest city in the country is included in the list of the most polluted cities. In addition to hazardous industries, the city is polluted with vehicle emissions, which amount to approximately 1,000,000 tons annually. This accounts for more than $90 \%$ of all harmful substances that pollute the city. From this it follows that in megalopolises the main source of urban pollution is motor vehicles.

According to experts in the global transport system, 70\% of the energy is consumed by road transport, including $50 \%$ of energy consumption by passenger transport (Fig. 1). The density of road networks is characteristic of large cities. The rapid development of the 
economies of the leading countries of the world, the processes of urbanization and globalization contribute to thegrowth of cities and emergence of urban transport networks. In cities with developed transport networks, they consist of a set of streets and transport passages served by various types of urban transport, as well as underground, ground and elevated transport lines. The adoption of measures to improve energy efficiency in the transport sector, taking into account the volume and variety of types of urban transport, will save significant amounts of energy and improve the environment.

There are three main strategies to improve energy efficiency in the transport sector:

- using efficient vehicles and shifting consumer demands for them;

- improving the quality of vehicles and fuels used;

- reducing the current demand for transport by preventing an increase in transportation of goods.

Shifting demand towards more efficient types of passenger transport is one powerful way to improve energy efficiency, which should encourage passengers to use public transport. Per capita energy consumption largely depends on the employment of the vehicles used. For different types of transportation, the specific energy consumption per passenger-kilometer varies significantly (Fig. 4). Reducing the use of personal motor vehicles by the population and increasing the use of public transport will significantly reduce energy consumption. Other types of alternatives are non-motor types of transport that do not require fuel. However, city dwellers accustomed to the comfort of using personal vehicles, might find it challenging to switch to alternative or public transport.

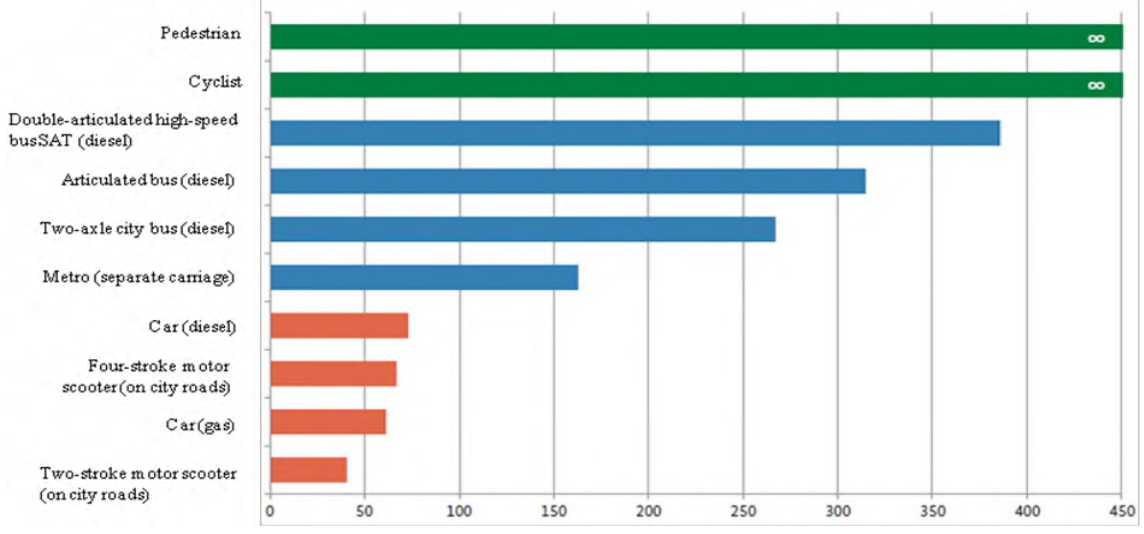

Fig.4. Energy efficiency for various types of urban transport Source: Adapted from GIZ (German Society for International Cooperation), 2011.

Modern technologies in the automotive industry, including the use of lightweight materials, reduction in engine weight and dimensions, and vehicle dimensions, significantly reduce energy consumption compared to an average passenger car. Improvement of fuels, in particular the use of alternative fuels such as natural gas, electricity, hydrogen, biodiesel, methanol, not only increases the energy efficiency of the transport system, but also significantly reduces environmental pollution. The global auto industry is focused on the production of vehicles with oil-based fuel consumption. In this regard, the development of alternative fuels with the inexpensive oil can be ineffective [13-14].

Optimization of urban transport systems, development of urban transport networks, reduction in the current demand for transport by preventing an increase in transportation volumes are the most rational ways to stimulate energy efficiency in the transport sector. The process of urban development contributes to a change in the spatial planning structure 
of territories, causing a rapid increase in the number of roads and traffic density of road transport. The total motorization of large cities resulted in the increase in traffic and frequent congestions on city streets and highways. In this regard, the loss of time for vehicles is measured hours, rather than in minutes.

International experience shows that the number of roads correlates with the intensity of traffic, resulting in increased traffic congestion. This leads to inefficient consumption of fuel and energy resources by land transport due to intense road congestion. For example, in 2005 there were about 3.5 million cars in Moscow. According to some estimates, on average, each of them spends 40-45 hours/month in traffic jams. For an hour of idling with 1 liter of fuel consumed, Moscow car owners lose about USD 2 billion a year. [15]. Inefficient consumption of fuel and energy resources by land transport can also be attributed to one of the important factors of environmental pollution.

\section{Concludions}

As a result, it should be noted that in modern cities, due to the increased density of urban development, transport networks, the number of factors affecting the urban space environemnt is increasing.

Based on the analysis performed, it can be argued that for sustainable urban environment the following measures have to be taken.

1. Competent planning of urban space and transport networks reduces road congestion and lead to efficient consumption of fuel and energy resources by transport.

2. Preventing an increase in transportation of goods reduces the current demand for transport.

3. Using modern technologies in the automotive industry, including lightweight materials, reducing the weight and dimensions of the engine and the size of the car reduces energy consumption.

4. Improving fuels, in particular, the use of alternative fuels such as natural gas, electricity, hydrogen, and biodiesel significantly reduces environmental pollution.

5. Taking into account the peculiarities of the built-up areas, the size and density of buildings has a positive influence of the aerodynamics of the area and reduces air pollution.

\section{References}

1. Yu. A.Tabunshchikov, N. V. Shilkin, AVOK 8, 12-14 (2004)

2. V.L.Kashintseva, D.A.Leonova, Journal Byulleten' stroitel'noy tekhniki 12, 27-30 (2018)

3. A. Giyasov, Yu.G.Barotov, Journal Ekologiya urbanizirovannykh territoriy 3, 90-97 (2018)

4. B.M. Shojhet, Ehnergosberezhenie 7, 62-66 (2007)

5. O.D. Samarin, Zhilishchnoye stroitel'stvo 1, 32 - 33 (2013)

6. B.I. Giyasov, Journal Vestnik MGSU 4, 17-21 (2012)

7. A.N. Kolubkov., AVOK 4, 8-10 (2005)

8. A.N. Kolubkov, AVOK 5, 14-15 (2004)

9. X. Li, J. Guo, Ch. Gao, Zh. Su, Z. Zhang, Network-based transportation system analysis: A case study in a mountain city, Chaos, Solitons \& Fractals 107, 256-265 (2018)

10. I.A. Bashmakov, Energosberezhenie 1, 62-67 (2010) 
11. H. Jeong, M. Park, W. Hwang, Eu. Kim, M. Han, The effect of calm conditions and wind intervals in low wind speed on atmospheric dispersion factors, Annals of Nuclear Energy 55, 230-237 (2013)

12. Q. Wang, Y. Wang, Y. Fan, J. Hang, Y. Li, Urban heat island circulations of an idealized circular city as affected by background wind speed, Building and Environment 148, 433-447 (2019)

13. J. Niemelä, Ecology of urban green spaces: The way forward in answering major research questions, Landscape and Urban Planning 125, 298-303 (2014)

14. K. S. Karimov, Kh. M. Akhmedov, M. Abid, G.N. Petrov, Effective management of combined renewable energy resources in Tajikistan, Science of The Total Environment 461-462, 835-838 (2013)

15. S.N. Vladimirov, Izvestia MSTU "MAMI" 1 (19), 79-81 (2014) 